\title{
THE IMPORTANCE OF EMOTIONAL INTELLIGENCE OF LEADERS IN CRISIS SITUATIONS
}

\author{
Mirjana Matić ${ }^{1}$ \\ DOI: https://doi.org/10.31410/LIMEN.S.P.2020.77
}

\begin{abstract}
In the modern world, today, due to rapid changes, development of technology, market demands, we can conclude that more than ever there is a danger of various types of crises. In this regard, more than ever before, it is necessary to understand what resources companies need to be more resilient to crises. This paper provides an overview of the theoretical framework, as well as research conducted in the field of emotional intelligence and crisis management. Many studies show that the importance of emotional intelligence of leaders in a crisis is great. Leaders who have a higher level of emotional intelligence possess certain skills that can be crucial to the organization in crisis situations. This paper aims to present the correlation that exists between emotionally intelligent leaders and crisis situations, taking into account several studies conducted in this area. All studies conducted have shown that there is a positive relationship between the emotional intelligence of leaders and crisis management. The conclusion is that examining the impact of the relationship between the emotional intelligence of leaders and the crisis is an exceptional framework that provides an opportunity for human resources to operate within organizations, as management of organizations themselves, seeking and shaping leaders with emotional intelligence skills.
\end{abstract}

Keywords: Emotional intelligence, Leader, Crisis management.

\section{INTRODUCTION}

$\mathrm{T}$

The first papers and research on emotional intelligence came from the authors' John Mayer and Peter Salovey, who, as part of their research, developed models and ways to measure and assess emotional intelligence. Emotional intelligence refers to the ability to recognize the importance of emotions and their mutual influence, as well as to judge and solve problems based thereon. Emotional intelligence includes the ability to perceive emotions, adapt to emotionally-related feelings, understand, and manage the information resulted from those emotions (Salovey \& Mayer, 1997; Salovey \& Mayer, 1990).

Nowadays, the importance of emotional intelligence is particularly reflected in the areas of business. Companies are increasingly interested in hiring managers with characteristics of a person with a higher level of emotional intelligence, or managers who will be able to recognize emotions both in themselves and their team members and to manage these emotions in the right way. In their research, Salovey and Mayer (1997) point to the importance of the relationship between an individual's developed skills and his/her emotional intelligence. People who have developed skills related to emotional intelligence understand and express their own emotions, recognize emotions in others, manage action, and use moods and emotions to motivate adaptive behavior.

1 University of Belgrade, Faculty of Organizational Sciences, Jove Ilića 154, Belgrade, Serbia 
The research that gave special importance to the topic of emotional intelligence in business is a 1998 article by Goleman, in which, having conducted research, Goleman concluded that $67 \%$ of all skills required by an individual in order to be successful in business results are actually based on emotional intelligence, that is, emotional abilities. Therein, Goleman divided the employee's skills into personal and social abilities. The first group includes abilities such as: self-awareness, management of oneself and one's own reactions, and motivation. The second group consists of abilities such as: empathy and social skills, that is, the ability to arouse desirable reactions in others.

Two years later, Goleman published a new article linking emotional intelligence to leader success, listing 4 key groups of abilities: self-awareness, self-management, social awareness, and social skills. Through each of these groups, the author states clear skills that contribute to the difference between exceptional and average managers, that is, provides the insight into skills needed by a true leader in order to effectively manage his/her team. (Goleman, 2000). Boyatzis (1999), drawing on Goleman's research, found that emotional skills, in order to have an impact on management performance, must permeate all four groups of emotional skills. He argues that out of all the skill groups, self-management is the most important, due to the impact it has on other groups, it has the most significant effect on business success results (Boyatzis, 1999).

On the other hand, it is clear that crisis is a term that is related to every segment of human life and greatly affects the satisfaction thereof. When we look at a person's working life, we can say that a person spends a third of his/her life at work. In that case, possible crises of companies or markets can certainly have a significant impact on employees. However, as the time we live in requires adaptation to all changes that are fast, dynamic, and often without clear instructions for adapting to a new process or change in an organization, personality structure of an individual, his/her energy, assertive communication and the ability to react to change in the right way in a short time thus become more important. The role of a leader in all times of change and crisis is to help his/her team maintain efficiency and set results, as well as motivation and a healthy, collegial relationship. Successful team management is more of an emotional than a cognitive process, because research shows more significant and better results in motivating team members through emotion, compared to the use of logic and cognitive mechanisms (Ilić, 2008).

This paper aims to determine, through research in the field of emotional intelligence and crisis management, whether there are positive or negative correlations between emotionally intelligent leaders and their crisis management. Identification of this relationship aims to produce certain conclusions, which can help companies in adopting strategies for establishing organizations more resilient to crises.

\section{EMOTIONAL INTELLIGENCE AND CRISIS MANAGEMENT ABILITY}

Due to all of the above, it is important to understand the way in which leadership and developing a leader's emotional intelligence can have a beneficial effect in times of crisis. Although the assumption that poor crisis management greatly affects the creation of significant losses in any crisis, it seems that human resources as well as other factors also affect it. Modern understandings within the field of human resources characterize human strength with unlimited resources. In addition, the ability to think and solve problems increases one's importance. Experts in this field perceive human resources to be so valuable that they consider any costs in 
this area as an investment. Investing in the development of emotional intelligence of leaders in the organization can make that organization healthier and thus more resilient to crisis situations.

During the crisis, it was noticed that all leaders involved in solving it, used their cognitive resources to solve the situations, dealing with the problems of the crisis daily, often not including any other resources (Bargh \& Chartrand, 1999). The way of team leading is important in that sense, so even changes in leadership styles can affect overcoming the crisis. As crisis implies a specific situation, it affects the cognitive overload of a leader, which further creates a blockage in the conscious perception of the leader's actions, as well as his/her personal assessment of his/her own results and management efficiency (Lord \& Maher, 1993).

As stated before, Goleman (2000) defines 4 key groups of abilities within emotional intelligence: self-awareness, self-management, social awareness, and social skills. Soltani, I., Shahsavari, M., Moradi, M. (2014) conducted a case study, published in the International Journal of Academic Research in Business and Social Sciences, presenting the relationship of each of these four abilities of emotional intelligence with the ability to manage crisis. In a total of 130 surveyed managers in Isfahan Province (Iran), the results showed that there were positive correlations between emotional intelligence and crisis management. Of the total number of respondents, $76 \%$ were male and $23 \%$ female. Regarding the importance of the position, $9 \%$ of respondents represented the position of top management, $21 \%$ of middle management and $70 \%$ of the first-level management. The analysis proved that, with a coefficient of 0.58 , emotional intelligence affected the ability to manage crises, with a coefficient of 0.58 , self-awareness affected the ability to manage crises, with a coefficient of 0.71 , self-management affected the ability to manage crises, and with a coefficient of 0.51 , social awareness affected the ability to manage crises. However, this analysis also showed that there was a link between social skills and crisis management skills, but, with a coefficient of 0.05 , the analysis rejected this.

Research conducted by Mader and Smith (2009) confirmed the accuracy of the hypothesis that the effect of leader emotions in crisis situations on leader evaluation is realized through the effect of participants. This study proved that accepting responsibility had a great impact on team members, that is, that a leader who accepted responsibility in a crisis situation was more valued by his employees. It was also proved that a leader giving answers and showing emotions in crisis situations makes the members of the team see him as a leader (Arsovski, 2014).

Nowadays, most organizations are project-oriented, which means that project managers become modern leaders in such organizations, because their responsibilities related to the project are completely related to the project team, that is, the success achieved on the project is related to the success of project team management. On the other hand, project managers are specially prepared for crisis situations, as each project is a separate business venture, and therefore the risk of failure is higher. A study conducted in our area in 2012 by a group of authors investigated the correlations between the emotional intelligence of project managers and their position in the organization hierarchy, as well as the emotional intelligence of project managers and their level of education (Obradović et al., 2012). The study results showed that there was a positive correlation, that is, that project managers with higher emotional intelligence (over 4) are in higher positions and have a higher level of education. The research sample included 75 respondents, project managers from the top 10 companies in Serbia, according to the list of the top 100 most successful companies in Serbia (published by the Ministry of Finance). Of the total number of respondents, $43 \%$ were male and $57 \%$ female. In terms of position importance, $4 \%$ of respondents were from top management, $17 \%$ from 
executive management, $31 \%$ from operational management and $48 \%$ from middle management. The largest percentage of respondents had a university degree $55 \%$, followed by $21 \%$ of respondents with a master's degree, $17 \%$ with a high school diploma and $7 \%$ with completed doctoral academic studies. Research findings show that project managers from the field of top management (4.33) and project managers with completed doctoral academic studies (4.64) have the highest level of emotional intelligence. They are followed by project managers from the field of executive management (4.09). An interesting finding in this study is the correlation observed in gender and age structure with business experience and emotional intelligence coefficient (EQ). Comparing the gender structure with the emotional intelligence coefficient, female respondents are found to have a higher coefficient (3.91) than male respondents (3.67). A positive correlation was also observed by comparing the age structure with business experience and the emotional intelligence coefficient, that is, years of work and life experience have an impact on a higher level of emotional intelligence.

Through these studies, it can be clearly seen that there is an unbreakable link between emotional intelligence and crisis management. The correlations in these studies go in a positive direction, which suggests that leaders with a higher level of emotional intelligence will manage crisis situations easier.

\section{DEVELOPMENT OF EMOTIONAL INTELLIGENCE SKILLS IN LEADERS IN CRISIS SITUATIONS}

Through numerous conducted studies, we can also see that when it comes to crisis situations, certain abilities within the emotional intelligence, which in normal business conditions would not be so important, are now more valued. The project named Emotional Intelligence Used in Crisis Manager Training: The Pandora project, implemented in the UK, basically shows the way of training of the special police units called "Gold commanders", which are believed to manage the crisis on a daily basis in their scope of work. They are in charge of control and strategy in dealing with extremely difficult and crisis situations (Mackinnon et al., 2000). The Pandora project puts emotional intelligence and crisis management in a special relationship, providing a special overview of the ways in which trainings are done and efficiency is improved in these situations. Through the project, theoretical frameworks were discussed, and practical exercises and trainings were implemented, so one of the conclusions was that the variables that particularly affect the individual in crisis situations were personality traits, leadership style, experience, self-efficacy, stress and anxiety.

In addition to the development of the emotional intelligence of the individual, or the leader, it is necessary to present the abilities that should be developed on a team level. In their paper published in 2001, Druskat and Wolff, in addition to individual skills, specifically listed the skills required of an emotionally intelligent group. In most of the literature, the development of emotional intelligence is tied to the individual, however, in crisis situations, emotionally intelligent teams, or emotionally intelligent companies, are of great importance. This case study singles out the following two skills important for a group:

Team self-assessment and feedback

It is extremely important for every leader to set a time to examine the effectiveness of the team by including the team in these activities. Creating measurable tasks, and then processing and measuring them, should be done transparently and with a team understanding of both processes. Transferring and communicating feelings between team members basically starts from the leader's open communication and his/her ability to express feelings about the team and the 
situations the team is going through. It is crucial to allow team members to give opinions and suggestions on processes they consider inefficient or insufficiently effective. Bass (1998) believes that effective group management cannot be carried out without the skills of reliability and conscientiousness of the leader.

In addition to these skills, the research also provides insights into ways in which the development of emotionally intelligent groups can be encouraged (Druskat \& Wolff, 2001):

1. Creating an affirmative environment. In this case, the optimism of the leader comes to the fore. It is important for the leader to encourage the important and positive mission of the group and to focus on what he/she can control. In crisis situations, the group must be reminded of other difficult situations that it has managed to successfully overcome. True leadership is based on the idea that leaders need to reach out to their followers emotionally and motivate them by identifying common values and higher purpose (Bass et al., 1987).

2. Proactive problem solving. We can say that this is most important for crisis management, for one reason, and that is foreseeing. Emotionally intelligent teams can anticipate problems and solve them before they occur or a crisis arises. It is important for this segment to take the initiative in order for the team to understand the situation and be more efficient. Changes are inevitable, necessary, expected, but they can lead in two directions: growth or crisis. It is clear that good decisions lead to the growth of the company, and that bad decisions lead to the crisis. Perhaps the most important knowledge we have about crises is that most crises are preceded by a series of prior warning signals. To prevent a major crisis, organizations only need to learn to read these early warning signals and respond to them more effectively (Mitroff, 1987).

Changing assumptions that are part of the organization's culture, including the concept of leadership, can create group resistance, as such changes enhance the group's defense mechanisms based on logical thinking (Schein, 2004). Therefore, it can be deemed that reexamining the cultural assumptions of the organization in itself is one of the crisis situations, for it generates a high level of stress. But on the other hand, it is clear that longer crises already produce higher levels of stress, but without the exhausting state (Smart \& Vertinski, 1977), which leads to the conclusion that periods of crisis are a good time for these types of changes (Lord \& Maher, 1993).

\section{CONCLUSION}

The skills required for effective crisis situations management are becoming more important over time. One of the reasons is the feeling that the modern age brings frequent periods of crisis, that is, that today any unfavorable situation can be considered a crisis situation. Markets are rapidly transforming due to people's needs for creativity, change, new technologies. The emotional intelligence of leaders provides a wide range of different social and personal skills, which, one can say, have become necessary in today's business model. All research conducted on the relationship between emotional intelligence and crisis, aimed to show the importance of this relationship, as well as the significance that arises from it. However, it seems that companies today are aware of this relationship and want to go in the direction of creating an emotionally intelligent organization. The disadvantage is that there are not sufficiently precise empirical frameworks for this field of research, or enough studies that would offer companies a way to strengthen their organization to leaders with higher EQ, develop them and thus create a more crisis-resistant organization. 
As research has shown, emotional intelligence is affected by age, as well as an individual's work experience. Studies have also shown that people with a higher level of education have a higher EQ. In support of this, and as a conclusion, we can say that companies, in setting their strategies for the development of managers and leaders, must keep in mind that it is necessary to further educate leaders, both in soft skills and expertise, but also, that it is necessary to create an organization that will nurture the values of protecting individuals who have been employed in the company for many years.

The role of the human resources sector in understanding this concept is significant. The skills of an emotionally intelligent leader, which can be pivotal in crisis situations, do not have to be so pronounced in the situations of regular business. It is up to the human resources sector to assess which positions may be crucial in possible crises. On the other hand, emotionally intelligent leaders can be good at estimating projected events, so there is a possibility that some crises may be affected preventively. Due to the understanding of the environment, the team they are in charge of, the need to adapt quickly to change, emotionally intelligent leaders will have a faster and clearer response, and then they will offer their team and organization a more concise and complete solution.

\section{REFERENCES}

Arsovski, S. (2014). Liderstvo i upravljanje promenama. 41. Nacionalna konferencija o kvalitetu, Kragujevac, Srbija, 22-23 maj, 2014, Fakultet inženjerskih nauka. 1-8.

Bargh, J. A., Chartrand, T. L. (1999). The unbearable automaticity of being. American Psychologist, 54(7), 462-479.

Bass, B. M. (1998). Transformational Leadership: Industrial, Military and Educational Impact. London: Lawrence Erlbaum Associates.

Bass, B. M., Waldman, D. A., Avolio, B. J., \& Bebb, M. (1987). Transformational leadership and the falling dominoes effect. Group and Organization Studies. 12: 7387.

Boyatzis, R. (1999). The financial impact of competencies in leadership and management of consulting firms. Department of Organizational Behaviour Working Paper, Case Western Reserve University, Cleveland.

Druskat, V., Wolff, S. (2001). Building the Emotional Intelligence of Groups. Harvard Business Review. 80-90.

Goleman, D. (2000). Leadership That Gets Results. Harvard Business Review, 2-17.

Goleman, D. (1998). What makes a leader? Harvard Business Review, 76(6), 92-102.

Goleman, D. (1998). Working with emotional intelligence. New York: Bantam Books.

Ilić, E. (2008). Emocionalna inteligencija i uspješno vođenje. Ekonomski pregled. 59(9-10), 576-592.

Lord, R. G. \& Maher, K. J. (1993) Leadership and information processing: linking perceptions and performance, London: Routledge.

Mackinnon, L., Bacon, L., Cortellessa, G., Cesta, A. (2000). Using Emotional Intelligence in Training Crisis Managers: The Pandora Approach. International Journal of Distance Education Technologies (IJDET). 11(2), 2-30.

Madera, J., Smith, D.B. (2009). The effects of leader negative emotions on evaluations of leadership in a crisis situation: The role of anger and sadness. The Leadership Quarterly 20. pg. 103114.

Mayer, J.D., Salovey, P. (1997). What is emotional intelligence. Emotional development and emotional intelligence. New York: Basic Books.

Mitroff, I., Shrivastava, P., Udwadia, E., F. (1987). Effective Crisis Management. The Academy of Management Executive 1(4), 283-292. 
Obradović, V., Jovanović, P., Petrović, D., Mihić, M., Mitrović, Z., (2012). Project Managers' Emotional Intelligence - A Ticket to Success. Procedia - Social and Behavioral Sciences. 74, 274-284. doi: 10.1016/j.sbspro.2013.03.034

Salovey, P. \& Mayer, J. (1990). Emotional intelligence, Imagination, Cognition, and Personality. 9, 185-211

Schein, E. H. (2004). Organizational culture and leadership. San Francisco: JosseyBass.

Smart, C., \& Vertinsky, I. (1977). Designs for Crisis Decision Units. Administrative Science Quarterly. 22, 640-657.

Soltani, I., Shahsavari, M., Moradi, M. (2014). The Impact of Emotional Intelligence on Crisis Management Capabilities Case Study: Small and Medium Enterprises in the Province of Isfahan. International Journal of Academic Research in Business and Social Sciences. 4(1), 415-423. doi:10.6007/IJARBSS/v4-i1/538 